Europe's Journal of Psychology, 7(2), pp. 374-394

www.ejop.org

\title{
Women's body image and the role of culture:
}

\section{A review of the literature}

\author{
Savita Bakhshi \\ London Metropolitan University
}

\begin{abstract}
Body image can be described as a combination of a person's perceptions, feelings and thoughts about his/her body and their general physical appearance. Self-perceptions are important to examine because they can have implications for a person's psychological and physical health. Past research has shown that culture plays a significant role in forming appearance ideals and that these vary for women of different cultures. The purpose of this article was to review the present literature on the prevalence of negative body image in women of different ethnic groups living in Western cultures. The similarities and differences between cultures in terms of negative body image in women were discussed followed by an examination of the role of acculturation in the development of negative body image. The findings showed that a significant proportion of women of different ethnicities are dissatisfied with their bodies and many are dieting to lose weight. The similarities between the groups indicated that the effect of non-Western cultures that previously promoted larger, more realistic body ideals is now diminishing. Thinner body ideals are now being reinforced for all women regardless of culture and ethnicity, thereby increasing the vulnerability towards developing a negative body image. The role of individual differences and the implications of this change are also discussed in this article.
\end{abstract}

Keywords: body image, culture, ethnicity, women, body ideals, body dissatisfaction, dieting behaviour.

Body image can be described as a combination of a person's perceptions, feelings and thoughts about his/her body and their general physical appearance (Cash \& Henry, 1995). It is usually conceptualised as an individual's body size estimation, evaluation of body attractiveness and emotions associated with their body shape 
and size (Cash \& Henry, 1995; Grogan, 2006). Szymanski and Cash (1995) proposed that body image consists of 2 components: 1) cognitive appraisal and associated emotions concerning an individual's own physical appearance, and 2) the extent of appearance investment. This research indicates that an individual's subjective experiences of their body may be more powerful than how they look in reality (Cash, 2004). These self-perceptions are important to examine because they can have implications for psychological and physical health, and can influence whether an individual has a positive or negative body image. Past research has found that certain traits are perceived as being associated with having a positive body image, including: happiness (Grogan, 1999), health (Bush, Williams, Lean \& Anderson, 2001), success (Stice, 1994; McKinley, 1999), attractiveness and intellect (Ogden, 1992, 2010), psychological and physical self-control (Ogden, 2010), high self-esteem (Swami, Airs, Chouhan, Padilla Leon \& Towell, 2009), and generally being satisfied with one's body (Wood-Barcalow, Tylka \& Augustus-Horvath, 2010).

Negative body image has been reported widely across different samples, and a variety of different psychological, social, cultural and demographic factors have been found to influence this state (see Grogan, 1999, for a review). Body dissatisfaction is one psychological and cognitive aspect of negative body image. It has been defined as: "a discrepancy between perceptions of reality versus those of an ideal...' (Ogden, 2004, p. 141) and is made up of an individual's own subjective experiences of their appearance. Body dissatisfaction stems from within the individual as they may have distorted perceptions about their body (i.e. perceiving the body bigger or smaller than it actually is). Ogden $(2004,2010)$ proposes that body dissatisfaction can be thought of and assessed in three ways: 1) distorted body size estimation - perceiving the body larger than it really is, 2) discrepancy from the ideal - a discrepancy between how an individual perceives themselves and how they want to look, and 3) negative feelings and cognitions towards the body - the most frequent way of assessing body dissatisfaction by asking questions such as 'Do you worry about parts of your body being too big?' In contrast to general body image, body dissatisfaction may also be influenced by others' perceptions of the self. Fallon (1990) described body size as 'the way people perceive themselves and, equally important, the way they think others see them'. This suggests that personal and perceived others' ideals are important influences on body dissatisfaction.

The main behavioural effects of negative body image (and indeed body dissatisfaction) is a need to alter one's body shape and weight through restrictive eating, dieting, physical activity and/or other weight loss methods (Anderson, Eyler, Galuska, Brown \& Brownson, 2002). Dieting is often used to lose and/or maintain weight, along with an increase in physical activity and other weight loss methods 
(i.e. medical advice). The word 'dieting', however, is problematic as it can have different meanings for different people (French \& Jeffery, 1994; Neumark-Sztainer \& Story, 1998; Andersen, Cohn \& Holbrook, 2000). Dieting behaviour may include: changes in eating patterns, unhealthy eating behaviours (i.e. low calorie diets, diet pills, fad diets), associated harmful behaviours (i.e. vomiting and laxative use), and dieting to the extreme, resulting in conditions such as anorexia and bulimia nervosa and other eating disturbances (Breitkopf \& Berenson, 2004). Generally, diets can be expensive if dieters are asked to eat particular foods and/or consume specific pills, and potentially dangerous if little or no food is consumed, leading to physical and psychological difficulties (Andersen et al., 2000). It is important to acknowledge that people displaying such behaviours come in all shapes and sizes, but their actual size does not matter; what motivates them to diet (and/or lose weight) is their perceived size (Ogden, 1992). People may go on a diet or attempt to lose weight because they feel fat and not necessarily because they are overweight (Hill, Oliver \& Rogers, 1992). Therefore, self-perceptions of weight can have negative effects on health because they motivate dieting, weight loss and exercise behaviours in order to increase body satisfaction.

The purpose of this article is to review the present literature on the prevalence of negative body image in women of different ethnic groups living in Western cultures. It is important to investigate negative body image in different groups so that any areas of concern within specific groups can be identified and addressed as appropriate (Holmqvist \& Frisen, 2010). A brief overview of the body ideals in Western and non-Western cultures will be presented, followed by the similarities and differences between cultures in terms of negative body image in women. Finally, the role of acculturation in the development of negative body image will be examined. A detailed discussion of the various factors that influence the similarities and differences between groups are beyond the scope of this paper, but it is anticipated that these will be examined in future articles.

The role of culture in body image development

Although the terms ethnicity, culture and race have been used interchangeably in past research, it is important to differentiate between these terms for the purposes of this review. Williams (2007) proposes that ethnicity 'emphasises the differentiation between groups in terms of their religious, ancestral, cultural and social backgrounds, and with the belief that ethnic groups are bound together by shared attitudes, behaviours and experiences' (p. 35). Culture, on the other hand, has been described as a: "...society that shares and transmits behaviors to its members..." (as 
cited in Wildes, Emery \& Simons, 2001, p. 522). Therefore, a culture may be shared by a society (i.e. everyone living in the UK), or smaller ethnic groups living within the UK (i.e. South Asians). It is important to remember, however, that 'cultural boundaries are not always as clear-cut as the borders between countries.' (Holmqvist \& Frisen, 2010 , p. 135), thus we need to exercise caution when interpreting findings. Culture plays a significant role in forming appearance ideals, including ideal body shapes and sizes (Fallon, 1990; Wiseman, Gray, Mosimann \& Ahrens, 1992), and it is widely recognised that these vary for women across societies and cultures. The ideal female body shapes and sizes have changed over the last century, and definitions of what it means to be attractive and healthy have been modified as a result.

Body ideals in Western cultures

Over the last century, the ideal female body in the West has decreased significantly in terms of weight and size, even though the average woman in Western cultures has become larger over the years (Wiseman et al., 1992). Previously in the West, the female body was represented with a full stomach, rounded hips and breasts (Grogan, 1999). Furthermore, larger body size ideals were considered as ideal as they represented wealth, prosperity and health (Thompson, Heinberg, Altabe \& Tantleff-Dunn, 1999), as well as being a symbol of fertility (Fallon, 1990). Women are now encouraged (and indeed expected) to be thin and slender, which is linked to attributes such as sexual attraction, fitness, success and self-control (Wykes \& Gunter, 2005; Cheney, 2010). (A detailed review on how the female ideal body shape has changed over the twentieth century can be found in Grogan, 1999). It is expected that people have control over their body weight and shape, and that an individual can achieve the ideal body with minimal effort (Vartanian \& Herman, 2006). However, although women continue to accept the thin societal ideal as a goal, these ideals have been criticised for informing individuals that body shape and weight are flexible, and that these ideals are achievable, whereas this may not be the case in reality (Pompper \& Koenig, 2004; Wood-Barcalow et al., 2010).

Body ideals in non-Western cultures

Nasser (1988) argued that the emphasis on thinness in the Western cultures may be a culture-bound syndrome, as thinness is devalued and deemed unattractive in many non-Western cultures, where larger body sizes are considered attractive (Furnham \& Patel, 1994; Cachelin, Monreal \& Juarez, 2006; Cheney, 2010). For example, Nasser (1988) suggested that for a Punjabi Indian to greet you with a saying of you "look fat and fresh today" is regarded as a compliment. In Arabic cultures, thinness is regarded as socially undesirable and bigger body sizes are symbolic of fertility and 
womanhood. Furthermore, larger shapes in non-Western cultures also stand for affluence and longevity in countries such as China and India. Other groups such as African Americans and Hispanics have also been shown to adopt culture-specific ideals that place less emphasis on achieving the thin ideal and show a greater acceptance of larger body sizes (Demarest \& Allen, 2000; Fitzgibbon, Blackman \& Avellone, 2000; Cachelin, Rebeck, Chung, \& Pelayo, 2002).

Rubin, Fitts \& Becker (2003) found that whereas White Western women often have a fixed concept of beauty (i.e. thinness), African American groups may define beauty through other aspects such as attitude, style, dress and personality (Flynn \& Fitzgibbon, 1998; Cheney, 2010; Kronenfeld, Reba-Harrelson, Von Holle, Reyes \& Bulik, 2010). Hispanic women also value other aspects of their appearance such as style and grooming, which leads to an acceptance of different body shapes and sizes (Wood-Barcalow et al., 2010). In an investigation of idealised body image standards in two generations of Hispanic women aged between 18-35 and 36 and over, Pompper \& Koenig (2004) found that Hispanic women are also more accepting of larger figures. They found that the both groups were more accepting of larger and curvier figures, which were perceived as healthy looking.

Warren, Gleaves, Cepeda-Benito, del Carmen Fernandez and Rodriguez-Ruiz (2005) proposed that ethnicity protects against the development of a negative body image as non-Western cultures provide people with larger, more realistic and attainable physical ideals (Rubin et al., 2003; Swami, Neto, Tovée \& Furnham, 2007). In India, for example, the prevalence of eating disturbances are rarely reported, perhaps due to the traditional Indian culture which does not encourage thinness as a symbol of feminine beauty (Dasgupta, 1998; Malhotra \& Rogers, 2000; Furnham \& Adam-Saib, 2001). In non-Western cultures, less value is placed on physical appearance as a defining feature of woman's worth, role in society and an indicator of success (Bush et al., 2001).

This is in contrast to the West where women's appearance is viewed as important feature for competitiveness, achievement and professional success (Stice, 1994; McKinley, 1999; Cheney, 2010). Ethnic minorities may have comparable levels of awareness of the thin ideal but may not internalise such information because of an affiliation with a culture of origin that does not support such values and ideals (Wood-Barcalow et al., 2010). Thus, identifying aspects of non-Western cultures may protect against the development of a negative body image (Warren et al., 2005). 
Negative body image in Western cultures

Ethnic group differences

The research cited above indicates that the standards and ideals of physical attractiveness vary across cultures and may contribute to the development and maintenance of a negative body image (Miller \& Pumariega, 2001). The prevalence of negative body image appears to vary among different groups, and change with time as cultures evolve. The prevalence of negative body image has been investigated in early, middle and later adulthood women of different ethnic groups in mainly North America and the UK. In an overview, Grogan (1999) found that body dissatisfaction was more frequent in British and American White women compared to other groups such as Black, African American, Hispanic and Asian women. Neff, Sargent, McKeown, Jackson and Valois (1997) found that most young African Caribbean and Asian women showed more body satisfaction and fewer weight concerns, whereas White women were more likely to consider themselves as overweight and to engage in unhealthy weight management practices. Anderson et al. (2002) compared body satisfaction levels of Hispanic, non-Hispanic Black, American Indian/Alaskan native and non-Hispanic white women aged 40 and older. They found that Hispanic, non-Hispanic Black and American Indian/Alaskan native women were more likely to express body size satisfaction compared to non-Hispanic white women.

In a study looking into ethnic group differences in positive body image, Swami et al. (2009) found that Hispanic women showed the highest body appreciation scores, followed by African Caribbean and White Caucasian women. In addition, Kronenfeld et al. (2010) found that African American women were also more likely to select a smaller figure to represent their current size, larger figures as their ideals and overall had lower body dissatisfaction compared to White women. Together, these findings support past research which has shown that young Black and Hispanic girls are happier with their bodies compared to White girls, as they prefer higher weights and are more accepting of larger body sizes (Wardle \& Marsland, 1990; Lynch, Heil, Wagner \& Havens, 2007). Swami et al. (2009) also found that South Asian women did not have a more positive body image than White women, which also supported earlier research that indicated that this group is now at risk of developing negative body image.

Other research has also shown that there may be few differences between different ethnic groups for aspects such as body weight and shape concerns (Dolan, Lacey \& 
Evans, 1990). In a meta-analysis of the literature, Grabe and Hyde (2006) investigated body dissatisfaction levels among Asian American, Black, Hispanic and White women. Looking specifically at White women, they found that their body dissatisfaction levels did not differ when compared to Asians and Hispanics, but they reported higher levels of body dissatisfaction than Black women. When Black women were compared to Hispanics, higher levels of body dissatisfaction were reported by the latter group, but no differences were found when compared to Asians. Lastly, Asian and Hispanic women had similar levels of body dissatisfaction. The analysis showed that body dissatisfaction is still the least prevalent in Black women, but other non-White groups are now showing similar rates of body dissatisfaction when compared to Whites. Furthermore, the outcomes of studies may depend on the groups that are compared, and so to conclude Whites are more dissatisfied than non-White groups may be incorrect (Dolan et al., 1990; Cummins \& Lehman, 2007; Holmqvist \& Frisen, 2010).

Shaw, Ramirez, Trost, Randall and Stice (2004) also found few ethnic group differences for eating pathology and the internalisation of the thin ideal. Consistent with past research, Black and Hispanic women showed less internalisation of the thin ideal compared to Whites and Asians, indicating that the two former groups are still protected to some extent as they idealise larger weights and sizes. However, there were no ethnic group differences for the eating disorder symptoms (i.e. weight and shape concerns and fear of fat), and eating disorder risk factors (i.e. pressure to be thin, body dissatisfaction and the influence of family, friends and peers), which suggests that there may be fewer differences between the groups now, and only some factors may protect against negative body image in non-White groups. Other non-academic research shows different patterns. The Dove report (2004) showed that African-American and Hispanic women had more positive feelings about their looks compared to White Caucasian women aged 20-65 years. Fifty-nine percent of African-Americans and $60 \%$ of Hispanics liked the way they looked, compared to $51 \%$ of White women, and many rated their looks above average, although the differences were less pronounced between the groups (African-Americans 41\%, Hispanics $38 \%$ and Whites 35\%). Together, this research seems to indicate that White women have more body and weight-related concerns, compared to other groups.

Negative body image in Black, Hispanic and White women

Much research has focused on investigating figure preferences and negative body image differences between White and Black women, some of which has highlighted the relationship between body image and obesity risk in Black women. Gluck and Geliebter (2002) found that African American women chose a larger ideal as their 
preferred body size, and showed less body discrepancy between their actual and ideal figures compared to White women. Allan, Mayo and Michel (1993) found an effect of social class as Black women of lower social economic groups were heavier in weight, perceived themselves as heavier, and believed a heavier body looked attractive compared to Black women of a higher social economic group and White women. Furthermore, these women had to become heavier than the other groups before they felt they were overweight, indicating that this particular group may have a wider range of body shapes and sizes that are perceived as normal and attractive, even though they are actually overweight (Paeratakul, White, Williamson, Ryan \& Bray, 2002). Flynn and Fitzgibbon (1998) also found that Black women chose heavier ideals than White women, and were less accurate in perceiving their weight.

Reviews of the literature have also shown that Black American women generally experience less body dissatisfaction, weight concerns and diet less than White American women (Striegel-Moore, Wilfley, Caldwell, Needham \& Brownell, 1996; Wildes et al., 2001; Gluck \& Geliebter, 2002; Grabe \& Hyde, 2006; Roberts, Cash, Feingold \& Johnson, 2006). Altabe (1998) also found that African Americans had the most positive general body image, when compared to White, Hispanic and Asian women. In their examination of weight reduction behaviours, Breitkopf and Berenson (2004) found that low-income African American women were less likely to diet (i.e. eat less or differently to lose weight) and purge (including vomiting and/or using of laxatives or diuretics) compared to White and Latina women of similar socioeconomic groups. They also exercised less frequently compared to the others groups, even though a significant proportion of the sample had a BMI of 25 and over.

Traditionally, Hispanic women have also been considered protected from negative body image development and disordered eating (Rubin et al., 2003; Cheney, 2010). Like Black women, Hispanic women may also report that they do not relate to the thin ideals as the Hispanic culture is more accepting of larger shapes and sizes that are considered attractive (Pompper \& Koenig, 2004; Cheney, 2010). Such shapes and sizes are also reflected in the female body preferences chosen by men. In a study looking at female body weight and shape preferences outside of North America, Swami et al. (2007) found that British, Spanish and Portuguese men chose different figures to represent female attractiveness. There was a stronger preference for a more shapely body shape in Spain and Portugal, although all the groups showed a preference for figures at the lower end of the BMI scale. The authors proposed that local factors may play a role in the acceptance and preference of larger figures in counties such as Spain and Portugal, including a relaxed attitude to eating and weight. Wardle, Hasse and Steptoe (2006) also reported similar findings 
as women from the Mediterranean felt less overweight compared to other groups, indicating the importance of local factors in influencing attitudes to body weight and shape. The influence of media is also important in these cultures as it shows women who are conforming to the cultural ideal. This helps to endorse the larger ideal, compared to predominantly Western cultures where the thin ideal is portrayed (Pompper \& Koenig, 2004).

These findings may also be due to a tolerance of higher weights and a flexible cultural standard of attractiveness and body shapes (Paeratakul et al., 2002; Allan et al., 2003; Schwartz \& Brownell, 2004). Black and Hispanic women who are exposed to the thin Western ideal may not internalise it due to their cultural background. Historically, lower weights were associated with poverty in Black societies, whereas heavier bodies were seen to represent health, wealth and power (Flynn \& Fitzgibbon, 1998). Although this view is helpful in promoting a positive body image in Black and Hispanic women, it places them at a higher risk on obesity than Whites, as they may chose to lose weight at a higher body weight and/or when they are a larger shape (Allan et al., 2003; Kronenfeld et al., 2010). This acceptance and compliance to their culture-specific beauty ideals may lead to a high prevalence of overweight and obesity in these groups, resulting in various health complications (Williams, 2007).

Fitzgibbon et al. (2000) studied the association between BMI and body dissatisfaction in White, Hispanic and Black women. They found that whereas White women experienced body dissatisfaction at a lower BMI, Black and Hispanic women did not report body dissatisfaction until they were overweight (as assessed by their BMI). But people may not always be accurate in perceiving their weight, which can have implications for their health. Paeratakul et al. (2002) found that self-perceptions of overweight were the highest in White women, compared to Black and Hispanic women. These results indicate that Black and Hispanic women may be susceptible to overweight and obesity as they do not have an accurate perception of their body weight. This, in turn, will lead to increased obesity within these groups, as well as other related health implications.

Other studies have indicated that these groups are no longer immune from negative feelings about the body (Cheney, 2010). Studies have shown that Hispanic girls become strongly affected by the Western culture with increasing levels of integration, leading to higher levels of body dissatisfaction (Fitzgibbon et al., 2000; Cheney, 2010). This may be especially true in younger Hispanics who may be influenced by the Western media, which portrays larger and curvier figures as socially inacceptable, and thin and toned women as more attractive (Pompper \& Koenig, 2004). Altabe (1998) found that White and Hispanic Americans showed more 
weight-related and body image disturbance than Africans and Asians, indicating that the body image disturbances in Hispanics are becoming similar to those of Whites.

Negative body image in Asian women compared to other groups

The fact that Asian women showed less body size dissatisfaction than White women in Altabe's (1998) study implies that the Asian culture may still devalue thinness and consider larger body sizes as attractive (Nasser, 1988). Cachelin et al. (2002) found that Asian women reported less body dissatisfaction than Whites, Hispanics and Blacks, and that they chose larger figures to represent underweight females than did Black women. Other studies have shown that Asian women are not protected against the development of body image and eating disturbances in a similar way that Black women are (Swami et al., 2009). Grabe and Hyde (2006) proposed that like Hispanics, Asians are also likely to conform to the thin ideal due to processes such as acculturation and integration into the dominant Western culture. Evans and McConnell (2003) looked at the way White, Black and Asian women responded to mainstream Western beauty ideals, and whether they compared themselves to these images. They found that Black women viewed the mainstream ideals as irrelevant and reported positive self-evaluations about their bodies. In comparison, Asian women were more likely to endorse these ideals, similar to White women, and also experienced greater body dissatisfaction compared to Black women.

Asian women also often report similar levels of eating disturbances, and have been found to have slightly more weight and diet concerns, and greater dietary restraint compared to Whites (Wildes et al., 2001; Cummins \& Lehman, 2007). Gluck and Geliebter (2002) found that prior to controlling for BMI White women had a greater body discrepancy between their actual and ideal figures than Asians. However, the two groups became similar afterwards and both showed a greater discrepancy compared to African women. Dolan et al. (1990) also found that British Asian women showed more disordered eating attitudes than White women. In their comparison of Asian and White Australian women, Jennings, Forbes, McDermott and Hulse (2006) found that Asians scored significantly higher for eating disorders psychopathology than the White group, as measured by the Eating Disorders Inventory-2. These findings indicate that Asian and White women are equally susceptible to eating disturbances. Increased risk of developing a negative body image has also been seen in young Asian girls compared to White girls (Mumford, Whitehouse \& Platts, 1991; Hill \& Bhatti, 1995; Furnham \& Adam-Saib, 2001). 
Body image concerns in Asian subgroups have also been investigated. Kennedy, Templeton, Gandhi and Gorzalka (2004) compared body satisfaction levels of Canadian Chinese, Indian and White (of European decent) undergraduates, and predicted that the Asian groups would report greater negative body image attitudes than Whites. The findings showed that there were significant differences in the body satisfaction levels of all three groups. In contrast to studies that have shown Whites have high levels of negative body image, the findings of this study showed that White women had the most positive body image, followed by Indians and Chinese. The Chinese participants were the most concerned with aspects such as their attractiveness, and least satisfied with their physical condition and body parts such as the face and breasts. Women of all ethnic groups reported a desire to be thinner. These results indicate Chinese and Indian populations are susceptible to negative body image just like Whites, and that ethnic group differences within the Asian population are likely to exist, as some aspects of body image may be more concerning to particular groups than others.

Dunkel, Davidson and Qurashi (2010) examined body satisfaction levels and internalisation to the Western ideals of appearance in younger and older Muslim and non-Muslim women in the US. The relationships between wearing Western and nonWestern clothes was also assessed. As predicted, younger and older Muslim women reported a discrepancy between their current and ideal body shapes, although this discrepancy was smaller compared to non-Muslim women of both age groups. Younger Muslim women who wore non-Western clothing were less likely to conform to the thin ideals than those who wore Western clothes, indicating the protective impact of culture on the internalisation of the thin ideal. Overall, the older women in both groups were less satisfied with their bodies and reported less pressure to conform to the thin ideal than younger women. Thus, although age and culture were protective for some groups, the findings indicate that there is an increased risk of developing a negative body image in younger and older Muslim women.

The majority of studies in this review so far have focused on aspects of negative body image, but it is also important to mention studies that have focused on characteristics of positive body image (Swami et al., 2009; Cheney, 2010). In interviews with Black, White and Asian American women, Wood-Barcalow et al. (2010) found that as well as accepting their bodies for the way they are, women also expressed love for their bodies through positive thoughts, emotions and protective behaviours. They spoke positively about various aspects of their body and appreciating its unique beauty and its practical functions. In contrast to the research conducted on weight-related attitudes, concerns and behaviours as discussed earlier, the women in this study made healthy food choices and consciously avoided 
disordered eating and dieting behaviours, thereby protecting their bodies from developing a negative body image. The research discussed so far has shown that ethnicity is an important influence on body dissatisfaction as body image relates to cultural values and norms, more highly in some groups than others.

\section{The role of acculturation}

As described earlier, recent studies show that there are now few differences between the satisfaction levels of White and non-White women, as more individuals and groups identify with the Western culture, compared to earlier. But, what implications does this have for people who have migrated to the Western culture, but yet still hold their native beliefs about body size, shape and weight? lyer and Haslam (2003) suggest that women who still identify with their culture of origin after migrating are protected against the unrealistic norms of the dominant culture (i.e. the West). However, increasing integration into the Western culture may increase vulnerability towards higher body dissatisfaction, as an individual is likely to adopt the culture's attitudes and norms, which may be in conflict with the beliefs of their native country (Saran \& Eames, 1980; Dasgupta, 1998; Talbani \& Hasanali, 2000; Cachelin ef al., 2006; Lynch et al., 2007; Cheney, 2010).

The level of acculturation ('the extent to which individuals have maintained their culture of origin or adapted to the larger society', Farver, Bhadha \& Narang, 2002, p.12) has been perceived as an important influence on body dissatisfaction and weight change (Wildes et al., 2001). Ball and Kenardy (2002) found a strong acculturation effect in South Asian women living in Australia, finding an association between the length of time spent in Australia and their weight and body shape concerns. The values and behaviours of these women became similar to those living in the host culture indicating that women who migrate to a Western culture may want to change their body shapes once settled into the new culture, which may initially lead to a negative body image. Jaeger, Ruggiert, Edlund, Gomez-Perretta, Lang, Mohammadkhani, et al. (2002) also found women living in India showed little discrepancy between their perceived and ideal body image, whereas Indian women living in the UK showed greater dissatisfaction with their body image compared to White women. This suggests that integration into a new culture could lead to body dissatisfaction (Cheney, 2010). Other findings have shown that the level of acculturation does not change the susceptibility of Asian women for developing eating disturbances (Jennings et al., 2006). 
Lopez, Blix and Gray (1995) investigated how length of residence affected actual and ideal body image perception in American Latina and non-Latina White women. The Latina participants were split into three groups: those born in the US, those who arrived before they were 17 years old, and those who immigrated at 17 years or older. No differences were found between the four groups for perceived body size, and actual and ideal figures chosen, even though they felt overweight. The length of residence was not associated with ideal body image, but the age at which the Latina women entered the US was important in forming the ideals. Those who migrated before they were 17 years old, had ideals similar to the Western thin ideal, compared to those who immigrated at 17 years or older. This research indicates that the earlier one migrates to the Western culture, the more likely it is that they will adopt the dominant culture's ideals.

However, some people may remain unaffected as they continue to conform to their own cultural ideals of appearance (Wildes et al., 2001; Swami et al., 2007). Bush et al. (2001) compared the body dissatisfaction levels of South Asian and Italian female migrants to women born in the UK. The results showed that few South Asians had tried to lose weight in the past or had experienced external pressures from others to change their body size and shape. However, when asked to choose ideal body shapes, all of the groups wanted to resemble one of the two thinnest shapes equating them with longevity, likelihood of marriage and job success, indicating that physical appearance is not the sole reason behind wanting to change one's body. Detailed accounts of the ways in which ethnically diverse women adjust their body image when living in Western cultures can be found in Cheney (2010).

\section{Conclusion}

The purpose of this literature review was to describe the prevalence of negative body image in women of different ethnic groups living in Western cultures. The research presented in this review has shown that a significant proportion of women of different ethnicities are dissatisfied with their body, many are dieting to lose weight and the prevalence of overweight and obesity is on the rise in different groups. The findings have been varied and it seems that the patterns are changing constantly, as more recent studies have shown fewer ethnic group differences for negative body image than studies conducted before and during the 1990s. The research presented has shown that women belonging to non-Western cultures living in Western cultures are increasingly adopting the Western standards of appearance, as opposed to the larger body weights, shapes and sizes that were considered attractive in their culture of origin (Cummins \& Lehman, 2007; Dunkel et al., 2010). The 
similarities between the groups in terms of their body dissatisfaction levels and dieting behaviour seem to indicate that the effect of non-Western cultures that previously promoted larger, more realistic body ideals (Nasser, 1988; Warren et al., 2005) is diminishing, and is now beginning to reinforce thinner body ideals for women (Malhotra \& Rogers, 2000; Mahmud \& Crittenden, 2007). This, in turn, increases vulnerability towards developing a negative body image (Mumford \& Choudry, 2000; Wildes et al., 2001; Gluck \& Geliebter, 2002; Grabe \& Hyde, 2006; Cummins \& Lehman, 2007).

Nevertheless, it is important to acknowledge that because body image is measured in different ways, it is difficult to draw concrete conclusions unless women from different cultures are compared directly in one study (Fallon, 1990; Holmqvist \& Frisen, 2010). It is also difficult to develop measures that are easy to administer, are applicable across different cultures and its people, and take into account the complexity and multifaceted nature of body image (Roberts et al., 2006; Kronenfeld et al., 2010). Therefore, one must keep these points in mind when interpreting the findings cited in the present review and others. A detailed review of the problems encountered in studies investigating cultural differences in body dissatisfaction can be found in Holmqvist and Frisen (2010).

Research examining cultural differences also often makes generalisations that every person will be exposed to the same cultural messages. Categorising and determining the extent to which people from different cultures living in one country have a similar lifestyle may be problematic because the cultural boundaries may not be explicit. Thus, we must also consider the role of individual differences, as people have unique environments and past experiences, which can lead to some people being more susceptible to negative body image than others. An individual's judgement of their ideal body weight and size are important considerations, as these can influence negative body image (Ogden, 1992, 2010; Wood-Barcalow et al., 2010). People are not always aware of, nor are they good at assessing their own body weight (Flynn \& Fitzgibbon, 1998; Fitzgibbon et al., 2000). This implies that even though there are certain external factors that may lead to appearance concern, it may be an individual's perceptions and the actions that they take, that determine how satisfied they are with their body (Schwartz \& Brownell, 2004). The next step is to review and examine the variety of different psychological, social, cultural and demographic factors have been found to influence the development of negative body image in women of different ethnicities. It is also essential to examine the reasons for why some groups tend to be more prone to developing a negative body image of themselves compared to other groups. It is anticipated that future articles will consider these areas. 


\section{References}

Allan, J.D., Mayo, K., \& Michel, Y. (1993). Body size values of White and Black women. Research in Nursing and Health, 16 (5), 323-333.

Altabe, M. (1998). Ethnicity and body image: Quantitative and qualitative analysis. International Journal of Eating Disorders, 23 (2), 153-159.

Andersen, A., Cohn, L., \& Holbrook, T. (2000). Making weight: Men's conflicts with food, weight, shape and appearance. Gurze Books.

Anderson, L.A., Eyler, A.A., Galuska, D.A., Brown, D.R., \& Brownson, R.C. (2002). Relationship of satisfaction with body size and trying to lose weight in a national survey of overweight and obese women aged 40 and older, United States. Preventive Medicine, 35 (4), 390-396.

Ball, K., \& Kenardy, J. (2002). Body weight, body image and eating behaviours: Relationships with ethnicity and acculturation in a community sample of young Australian women. Eating Behaviors, 3 (3), 205-216.

Breitkopf, C.R., \& Berenson, A.B. (2004). Correlates of weight loss behaviors among lowincome African-American, Caucasian, and Latina women. Obstetrics and Gynecology, 103 (2), 231-239.

Bush, H.M., Williams, R.G.A., Lean, M.E., \& Anderson, A.S. (2001). Body image and weight consciousness among South Asian, Italian and general population women in Britain. Appetite, 37 (3), 207-215.

Cachelin, F.M., Monreal, T.K., \& Juarez, L.C. (2006). Body image and size perceptions of Mexican American women. Body Image, 3 (1), 67-75.

Cachelin, F.M., Rebeck, R.M., Chung, G.H., \& Pelayo, E. (2002). Does ethnicity influence body-size preference? A comparison of body image and body size. Obesity Research, $10(3), 158-166$.

Cash, T.F. (2004). Body Image: past, present, and future. Body Image, 1 (1), 1-5.

Cash, T.F., \& Henry, P.E. (1995). Women's body image: The results of a national survey in the U.S.A. Sex Roles: A Journal of Research, 33 (1-2), 19-28. 
Cheney, A.M. (2010). "Most Girls Want to be Skinny": Body (Dis)Satisfaction Among Ethnically Diverse Women. Qualitative Health Research, published online 9 December 2010, doi: $10.1177 / 1049732310392592$.

Cummins, L.H., \& Lehman, J. (2007). Eating disorders and body image concerns in Asian American women: Assessment and treatment from a multicultural and feminist perspective. Eating Disorders, 15 (3), 217-230.

Dasgupta, S.D. (1998). Gender roles and cultural continuity in the Asian Indian immigrant community in the U.S. Sex Roles: A Journal of Research, 38 (11-12), 953-974.

Demarest, J., \& Allen, R. (2000). Body Image: Gender, ethnic, and age differences. The Journal of Social Psychology, 140 (4), 465-472.

Dolan, B., Lacey, J.H., \& Evans, C. (1990). Eating behaviour and attitudes to weight and shape in British women from three ethnic groups. British Journal of Psychiatry, 157, 523528.

Dunkel, T.M., Davidson, D., \& Qurashi, S. (2010). Body satisfaction and pressure to be thin in younger and older Muslim and non-Muslim women: The role of Western and nonWestern dress preferences. Body Image, 7 (1), 56-65.

Evans, P.C., \& McConnell, A.R. (2003). Do racial minorities respond in the same way to mainstream beauty standards? Social comparison processes in Asian, Black, and White women. Self and Identity, 2 (2), 153-167.

Fallon, A.E. (1990). Culture in the mirror: Sociocultural determinants of body image. In T.F. Cash and T. Pruzinsky (Eds.). Body Images: development, deviance and change (pp. 80109). New York: Guildford.

Farver, J.A.M., Bhadha, B.R., \& Narang, S.K. (2002). Acculturation and psychological functioning in Asian Indian adolescents. Social Development, 11 (1), 11-29.

Fitzgibbon, M.L., Blackman, L.R., \& Avellone, M.E. (2000). The relationship between body image discrepancy and body mass index across ethnic groups. Obesity Research, 8 (8), 582-589.

Flynn, K.J., \& Fitzgibbon, M. (1998). Body images and obesity risk among Black females: A review of the literature. Annals of Behavioral Medicine, 20 (1), 13-24. 
French, S.A., \& Jeffery, R.W. (1994). Consequences of dieting to lose weight effects on physical and mental health. Health Psychology, 13 (3), 195-212.

Furnham, A., \& Adam-Saib, S. (2001). Abnormal eating attitudes and behaviours and perceived parental control: A study of White British and British-Asian school girls. Social Psychiatry and Psychiatric Epidemiology, 36 (9), 462-470.

Furnham, A., \& Patel, R. (1994). The eating attitudes and behaviours of Asian and British school girls: A pilot study. International Journal of Social Psychiatry, 40 (3), 214-226.

Gluck, M., \& Geliebter, A. (2002). Racial/ethnic differences in body image and eating behaviours. Eating Behaviors, 3 (2), 143-151.

Grabe, S., \& Hyde, J.S. (2006). Ethnicity and body dissatisfaction among women in the United States: A meta-analysis. Psychological Bulletin, 132 (4), 622-640.

Grogan, S. (1999). Body Image: Understanding Body dissatisfaction in men, women and children. Routledge.

Grogan, S. (2006). Body image and health: Contemporary perspectives. Journal of Heath Psychology, 11 (4), 523-530.

Hill, A.J., \& Bhatti, R. (1995). Body shape perception and dieting in preadolescent British Asian girls: links with eating disorders. International Journal of Eating Disorders, 17 (2), 175 183.

Hill, A.J., Oliver, S., \& Rogers, P. (1992). Eating in the adult world: the rise of dieting in childhood and adolescence. British Journal of Clinical Psychology, 31, 95-105.

Holmqvist, K., \& Frisen, A. (2010). Body Dissatisfaction Across Cultures: Findings and Research Problems. European eating Disorders Review, 18 (2), 133-146.

Iyer, D.S., \& Haslam, N. (2003). Body image and eating disturbance among South-AsianAmerican women: The role of racial teasing. International Journal of Eating Disorders, 34 (1), 142-147.

Jaeger, B., Ruggiert, G.M., Edlund, B., Gomez-Perretta, C., Lang, F., Mohammadkhani, P., Sahleen-Veasey, C., Schomer, H., \& Lamprecht, F. (2002). Body dissatisfaction and its interrelations with other risk factors for Bulimia Nervosa in 12 Countries. Psychotherapy and Psychosomatics, 71 (1), 54-61. 
Jennings, P.S., Forbes, D., McDermott, B., \& Hulse, G. (2006). Acculturation and eating disorders in Asian and Caucasian Australian university students. Eating Behaviors, 7 (3), 214-219.

Kennedy, M.A., Templeton, L., Gandhi, A., \& Gorzalka, B.B. (2004). Asian body image satisfaction: Ethnic and gender differences across Chinese, Indo-Asian, and Europeandescent students. Eating Disorders, 12 (4), 321-336.

Kronenfeld, L.W., Reba-Harrelson, L., Von Holle, A., Reyes, M.L., \& Bulik, C.M. (2010). Ethnic and racial differences in body size perception and satisfaction. Body Image, 7 (2), 131136.

Lopez, E., Blix, G.G., \& Gray, A. (1995). Body image of Latinas compared to body image of non-Latina White women. Health Values, 19 (6), 3-10.

Lynch, W.C., Heil, D.P., Wagner, E., \& Havens, M.D. (2007). Ethnic differences in BMl, weight concerns, and eating behaviors: Comparison of Native American, White, and Hispanic adolescents. Body Image, 4 (2), 179-190.

Mahmud, N., \& Crittenden, N. (2007). A comparative study of body image of Australian and Pakistani young females. British Journal of Psychology, 98 (2), 187-197.

Malhotra, S., \& Rogers, E.M. (2000). Satellite television and the new Indian woman. International Communication Gazette, 62 (5), 407-429.

McKinley, N.M. (1999). Women and objectified body consciousness: Mothers' and daughters' body experience in cultural, development, and familial context. Developmental Psychology, 35 (3), 760-769.

Miller, N.M., \& Pumariega, A.J. (2001). Culture and eating disorders: A historical and cross-cultural review. Psychiatry, 64 (2), 93-110.

Mumford, D.B., \& Choudry, I.Y. (2000). Body dissatisfaction and eating attitudes in slimming and fitness gyms in London and Lahore: A cross-cultural study. European Eating Disorders Review, 8 (3), 217-224.

Mumford, D.B., Whitehouse, A.M., \& Platts, M. (1991). Sociocultural correlates of eating disorders among Asian schoolgirls in Bradford. British Journal of Psychiatry, 158, 222-228.

Nasser, M. (1988). Culture and weight consciousness. Journal of Psychosomatic Research, 32 (6), 573-577. 
Neff, J.V., Sargent, R.G., McKeown, R.E., Jackson K.L., \& Valois R.F. (1997). Black-White differences in body size perceptions and weight management practices among adolescent females. Journal of Adolescent Health, 20 (6), 459-465.

Neumark-Sztainer, D., \& Story, M. (1998). Dieting and binge eating among adolescents: What do they really mean? Journal of American Dietetic Association, 98 (4), 446-450.

Ogden, J. (1992). Fat chance: the myth of dieting explained. London: Routledge.

Ogden, J. (2004). Health Psychology. A textbook (3rd ed.). Open University Press.

Ogden, J. (2010). The psychology of eating: from healthy to disordered behaviour $\left(2^{\text {nd }}\right.$ ed.). Wiley-Blackwell.

Paeratakul, S., White, M. A., Williamson, D. A., Ryan, D. H., \& Bray, G. A. (2002). Sex, race/ethnicity, socioeconomic status, and $\mathrm{BMI}$ in relation to self-perception of overweight. Obesity Research, 10 (5), 345-350.

Pompper, D., \& Koenig, J. (2004). Cross-cultural-generational perceptions of ideal body image: Hispanic women and magazine standards. Journalism and Mass Communication Quarterly, 81 (1), 89-107.

Roberts, A., Cash, T.F., Feingold, A., \& Johnson, B.T. (2006). Are Black-White Differences in Females' Body Dissatisfaction Decreasing? A Meta-Analytic Review. Journal of Consulting and Clinical Psychology, 74 (6), 1121-1131.

Rubin, L.R., Fitts, M.L., \& Becker, A.E. (2003). 'Whatever feels good in my soul': Body ethics and aesthetics among African American and Latina women. Culture, Medicine, and Psychiatry, 27 (1), 49-75.

Saran, P., \& Eames, E. (1980). The New Ethnics. Asian Indians in the United States (Eds.). Praeger Publishers.

Schwartz, M.B., \& Brownell, K.D. (2004). Obesity and body image. Body Image, 1 (1), $43-$ 56.

Shaw, H., Ramirez, L., Trost, A., Randall, P., \& Stice, E. (2004). Body image and eating disturbances across ethnic groups: More similarities than differences. Psychology of Addictive Behaviors, 18 (1), 12-18. 
Stice, E. (1994). Review of the evidence for a sociocultural model of bulimia nervosa and an exploration of the mechanisms of action. Clinical Psychology Review, 14 (7), 633-661.

Striegel-Moore, R.H., Wilfley, D.E., Caldwell, M.B., Needham, M.L., \& Brownell, K.D. (1996). Weight-related attitudes and behaviors of women who diet to lose weight: A comparison of Black dieters and White dieters. Obesity Research, 4 (2), 109-116.

Swami, V., Airs, N., Chouhan, B., Padilla Leon, M.A, \& Towell, T. (2009). Are there ethnic differences in positive body image among female British undergraduates? European Psychologist, 14 (4), 288-296.

Swami, V., Neto, F., Tovée, M.J., \& Furnham, A. (2007). Preference for female body weight and shape in three European countries. European Psychologist, 12 (3), 220-227.

Szymanski, M.L., \& Cash, T.F. (1995). Body-image disturbances and self-discrepancy theory: Expansion of the Body-Image Ideals Questionnaire. Journal of Social and Clinical Psychology, 14 (2), 134-146.

Talbani, A., \& Hasanali, P. (2000). Adolescent females between tradition and modernity: gender role socialization in South Asian immigrant culture. Journal of Adolescence, 23 (5), 615-627.

The Dove Report: Challenging Beauty (2004). Unilever. Retrieved March 8, 2011, from http://www.campaignforrealbeauty.ie/supports.asp?id=328\&length=short.

Thompson, J.K., Heinberg, L..J., Altabe, M., \& Tantleff-Dunn, S. (1999). Exacting Beauty: Theory, Assessment, and Treatment of Body Image Disturbance. American Psychological Association. Washington, DC.

Vartanian, L.R., \& Herman, C.P. (2006). Beliefs about the determinants of body weight predict dieting and exercise behaviour. Eating Behaviors, 7 (2), 176-179.

Wardle, J., \& Marsland, L. (1990). Adolescent concerns about weight and eating: A social-developmental perspective. Journal of Psychosomatic Research, 34 (4), 377-391.

Wardle, J., Haase, A.M., \& Steptoe, A. (2006). Body image and weight control in young adults: international comparisons in university students from 22 countries. International Journal of Obesity, 30 (4), 644-651. 
Warren, C.S., Gleaves, D.H., Cepeda-Benito, A., del Carmen Fernandez, M., \& RodriguezRuiz, S. (2005). Ethnicity as a protective factor against internalization of a thin ideal and body dissatisfaction. International Journal of Eating Disorders, 37 (3), 241-249.

Wildes, J.E., Emery, R.E., \& Simons, A.D. (2001). The roles of ethnicity and culture in the development of eating disturbance and body dissatisfaction: A meta-analytic review. Clinical Psychology Review, 21 (4), 521-551.

Williams, E. (2007). Ethnicity and Health. The European Health Psychologist, 9 (2), 35-37.

Wiseman, C.V., Gray, J.J., Mosimann, J.E., \& Ahrens, A.H. (1992). Cultural expectations of thinness in women: An update. International Journal of Eating Disorders, 11 (1), 85-89.

Wood-Barcalow, N.L., Tylka, T.L., \& Augustus-Horvath, C.L. (2010). "'But I Like My Body"': Positive body image characteristics and a holistic model for young-adult women. Body Image, 7, 106-116.

Wykes, M., \& Gunter, B. (2005). The Media and Body Image: If Looks Could Kill. Sage Publications.

\section{About the author:}

Dr. Savita Bakhshi is a Research Fellow at the School of Psychology, London Metropolitan University. Her primary research interests include the relationships between body image, food, health, exercise and the media in different ethnic groups.

Address for correspondence: Savita Bakhshi, School of Psychology, Faculty of Life Sciences, London Metropolitan University, Calcutta House, Old Castle Street, London El 7NT

Email: s.bakhshi@londonmet.ac.uk 